\title{
Microvessel Morphology and Vascular Endothelial Growth Factor Expression in Human Colonic Carcinoma With or Without Metastasis
}

\author{
Tsuyotoshi Tsuji, Yoshihiro Sasaki, Masanori Tanaka, Norihiro Hanabata, \\ Ryukichi Hada, and Akihiro Munakata
}

First Department of Internal Medicine (TT, YS, NH, AM), Second Department of Pathology (MT), and Department of Medical Informatics (RH), Hirosaki University School of Medicine, Hirosaki, Japan

\begin{abstract}
SUMMARY: We quantified microvessel morphology and vascular endothelial growth factor (VEGF) expression in human colonic carcinoma with or without metastasis. The cancerous growth and the noncancerous section of surgical specimens from 36 patients with colorectal carcinoma (14 without metastasis and 22 with metastasis) were studied. Tissue slices immunostained with CD34 were processed for microvessel counts (per $\mathrm{mm}^{2}$ ), the mean diameter of microvessels $(\mu \mathrm{m})$, and the mean spatial direction of microvessels (degree), defined by the angle between the longitudinal axis of microvessels and the direction perpendicular to the surface of the mucosa. Tissue slices immunostained with anti-VEGF antibody were processed for total epithelial cell counts (per $\mathrm{mm}^{2}$ ), VEGF-positive cell counts (per $\mathrm{mm}^{2}$ ), and VEGF-positive ratio (\%). Carcinoma without metastasis had significantly larger microvessel counts $(213 \pm 77, p<0.01)$, larger microvessel diameter $(7.99 \pm 1.77, p<0.05)$, and larger spatial direction $(47.2 \pm 8.3, p<0.01)$ than normal tissue $(144 \pm 49$ for microvessel counts; $7.03 \pm 0.90$ for microvessel diameter; $39.5 \pm 6.6$ for spatial direction). Compared with carcinoma without metastasis, carcinoma with metastasis had a significantly larger microvessel diameter $(9.75 \pm 2.65, p<0.03)$ and lower microvessel counts $(180 \pm 92, p=0.51)$. Carcinoma without metastasis had a significantly larger VEGF-positive cell count $(1276 \pm 805, p<0.05)$ and larger VEGF-positive ratio $(53.6 \pm 39.3$, $p<0.05)$ than normal tissue $(571 \pm 553$ for VEGF-positive cell counts; $24.6 \pm 23.2$ for VEGF-positive ratio). Carcinoma with metastasis had a significantly lower total cell count $(1443 \pm 237, p<0.001)$ and lower VEGF-positive cell count $(716 \pm 463$, $p<0.05)$ than carcinoma without metastasis. With tumor progression, microvessel diameter significantly increased and microvessel counts decreased, which can be in part explained by VEGF expression. The microvessel diameter seems to be the dominant parameter responsible for cancer cell intravasation as the first step of metastasis. (Lab Invest 2002, 82:555-562).
\end{abstract}

$N$ eovascularization and the resulting microcirculation are essential for supplying nutrients and removing waste products during tumor cell proliferation (Jain, 1988). Microvessels also serve as the vehicle for tumor cells to metastasize to distant organs or tissues. Recently, microvessel counts have been quantified to investigate a possible correlation with the nature of colonic carcinoma: they have been reported to be correlated with the depth of invasion in early-stage colonic carcinoma (Saeki et al, 1997) and the presence or absence of metastasis (Takahashi et al, 1995, 1996, 1998) and have a predictive value for recurrence or metastasis (Frank et al, 1995; Takahashi et al, 1997).

Yamaura and Sato (1974) have analyzed the growth of microvessels in implanted tumor tissue using intravital microscopy and have divided the growth period into four stages according to changes in vascular morphology. Their study has demonstrated changes in microvessel diameter and microvessel counts along with the stages.

Received December 29, 2001.

This work was supported in part by a grant-in-aid for scientific research from the Ministry of Education, Japan (no. 11878772).

Address reprint requests to: Dr. Yoshihiro Sasaki, First Department of Internal Medicine, Hirosaki University School of Medicine, 5-Zaifu-cho, Hirosaki,036-8562, Japan. E-mail: gahiro@cc.hirosaki-u.ac.jp
Microvessel counts increased to peak at Stage 2, thereafter decreasing to almost 0 at Stage 4 . The mean microvessel diameter increased as the stage progressed. A comparable morphometry of microvessels has not yet been conducted in human colonic carcinoma. Furthermore, the mechanisms by which tumor microvessels are changed in number or morphology with tumor progression have been poorly understood. Vascular endothelial growth factor (VEGF) is a specific and critical growth factor for blood vessel formation (Dvorak et at, 1999; Ferrara, 1999), yet it remains to be determined how VEGF is involved in the mechanisms. With the progress of digital imaging technology, it has become possible to quantify the count or morphology of any element composing digitized microscopic pictures. The aims of this study were to quantify microvessel morphology and microvessel counts and VEGF expression in human colonic carcinoma by using immunohistochemistry and image processing and to correlate the variables with the presence or absence of metastasis.

\section{Results}

\section{Morphometric Variables Versus Disease Stage}

Morphometric variables in normal colonic tissue and carcinoma with or without metastasis are shown in 
Table 1. Carcinoma without metastasis had significantly larger microvessel counts $(213 \pm 77)$, larger microvessel diameter $(7.99 \pm 1.77)$, and larger spatial direction (47.2 \pm 8.3$)$ than normal control tissue (144 \pm 49 for microvessel counts, $p<0.01 ; 7.03 \pm 0.90$ for microvessel diameter, $p<0.03 ; 39.5 \pm 6.6$ for spatial direction, $p<0.01$ ). Compared with carcinoma without metastasis, carcinoma with metastasis had a significantly larger microvessel diameter $(9.75 \pm 2.65$, $p<0.05)$ but did not significantly differ in the other variables (180 \pm 92 for microvessel counts, $p=0.27$; $47.5 \pm 8.7$ for spatial direction, $p=0.94$ ). The maximum microvessel diameter in normal tissue, carcinoma without metastasis, and carcinoma with metastasis was 30,55 , and $71 \mu \mathrm{m}$, respectively.

To examine the differences in microvessel diameter among normal tissue and carcinoma with or without metastasis, the relative frequency of microvessels was plotted against the diameter. In normal tissue, the frequency showed the normal distribution with a peak diameter of $7 \mu \mathrm{m}$ (Fig. 1A). As the disease stage progressed, the number of small diameter vessels $(<10 \mu \mathrm{m})$ decreased, while the peak diameter remained unchanged (Fig. 1, B and C). The frequency of vessels $(<10 \mu \mathrm{m})$ was $87 \%$ in normal tissue, $75 \%$ in carcinoma without metastasis, and $64 \%$ in carcinoma with metastasis.

\section{Morphometric Variables as a Function of the Depth}

Microvessel Counts. In normal tissue, microvessel counts were 220 in the shallowest part of the mucosa (0 to $100 \mu \mathrm{m}$ ) and abruptly decreased to 100 , remaining constant at a depth of $>100 \mu \mathrm{m}$ (Fig. 2A). In carcinoma without metastasis, microvessel counts gradually decreased from 250 to 142 as the depth increased, and they were significantly higher in carcinoma without metastasis than in normal tissue at a depth of $>100 \mu \mathrm{m}$. Compared with carcinoma without metastasis, carcinoma with metastasis had small vessel counts, but the difference did not reach a significant level at any depth.

Microvessel Diameter. In normal tissue, microvessel diameter remained around $7.5 \mu \mathrm{m}$, with the largest diameter of $9.5 \mu \mathrm{m}$ in the deepest part of the mucosa; in carcinoma without metastasis, it decreased to 7.0 $\mu \mathrm{m}$, thereafter remaining constant at a depth of $>400$
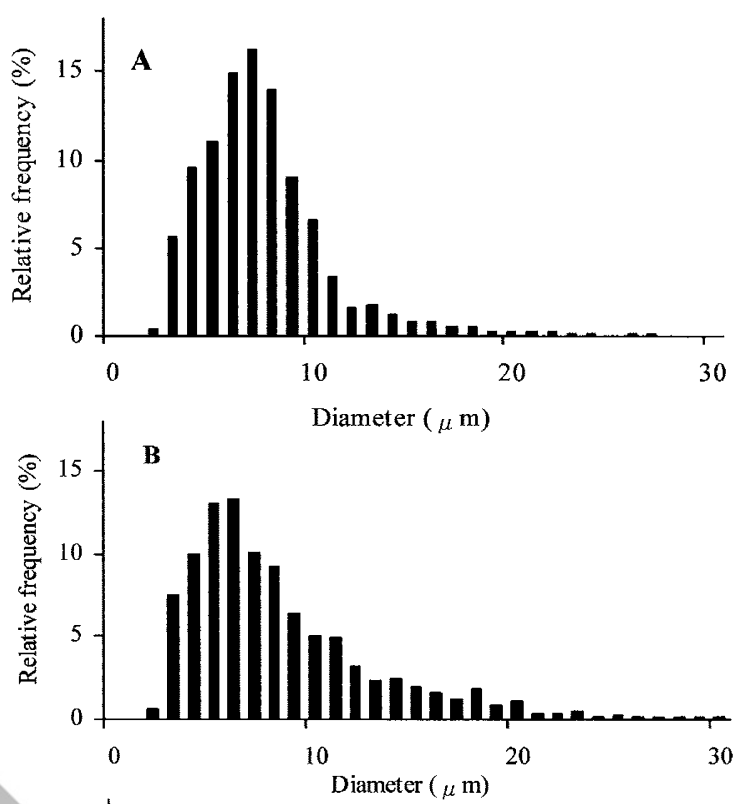

C

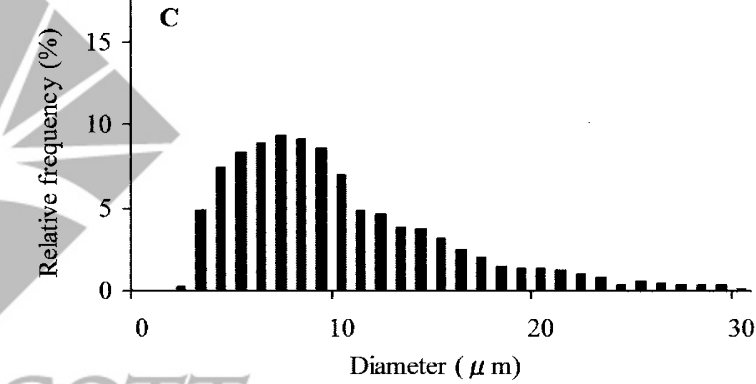

Figure 1.

The microvessel diameter-relative frequency histograms in normal mucosa (A), colonic carcinoma without metastasis (B), and colonic carcinoma with metastasis (C). The frequency of microvessels with a diameter $<10 \mu \mathrm{m}$ was $87 \%$ in normal tissue, $75 \%$ in carcinoma without metastasis, and $64 \%$ in carcinoma with metastasis.

$\mu \mathrm{m}$ (Fig. 2B). The difference in microvessel diameter between normal tissue and carcinoma without metastasis was significant at a depth of $<400 \mu \mathrm{m}$. However, there was no significant difference in this variable between carcinoma with or without metastasis at any depth except the depth of 400 to $500 \mu \mathrm{m}$.

Spatial Direction. In normal tissue, the spatial direction was $52^{\circ}$ at a depth of 0 to $100 \mu \mathrm{m}$ and abruptly decreased to $32^{\circ}$ and remained constant at a depth of

Table 1. Morphometric Variables of Microvessels in Normal Carcinoma Without Metastasis and Carcinoma With Metastasis

\begin{tabular}{lccc}
\hline & $\begin{array}{c}\text { Counts }\left(/ \mathrm{mm}^{2}\right) \\
\text { Mean } \pm \mathrm{SD}\end{array}$ & $\begin{array}{c}\text { Diameter }(\mu \mathrm{m}) \\
\text { Mean } \pm \mathrm{SD}\end{array}$ & $\begin{array}{c}\text { Direction (degree) } \\
\text { Mean } \pm \mathrm{SD}\end{array}$ \\
\hline Normal & $144 \pm 49$ & $7.03 \pm 0.90$ & $39.5 \pm 6.6$ \\
Carcinoma & $213 \pm 77^{a}$ & $7.99 \pm 1.77^{b}$ & $47.2 \pm 8.3^{a}$ \\
Without metastasis & $180 \pm 92^{c}$ & $9.75 \pm 2.65^{d}$ & $47.5 \pm 8.7^{c}$ \\
With metastasis & & \\
\hline
\end{tabular}

${ }^{a}$ Differences are significant at $p<0.01$ compared with normal.

${ }^{b}$ Significant at $p<0.05$ compared with normal.

${ }^{c}$ Not significant compared with carcinoma without metastasis

${ }^{a}$ Significant at $p<0.03$ compared with carcinoma without metastasis. 

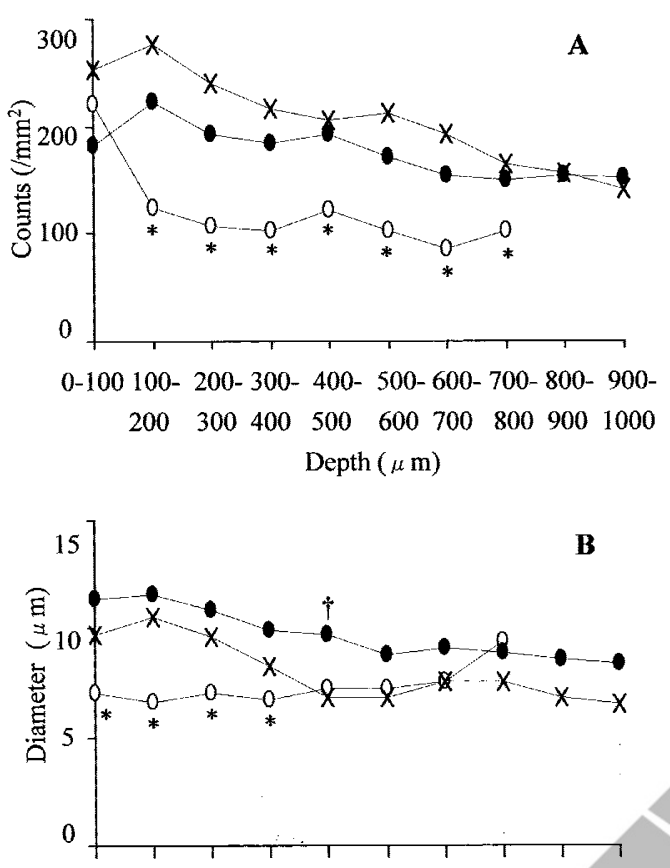

$0-100100-200-300-400-500-600-700-800$ - 900 -

$200 \quad 300400 \quad 500 \quad 600700 \quad 800 \quad 900 \quad 1000$ Depth $(\mu \mathrm{m})$

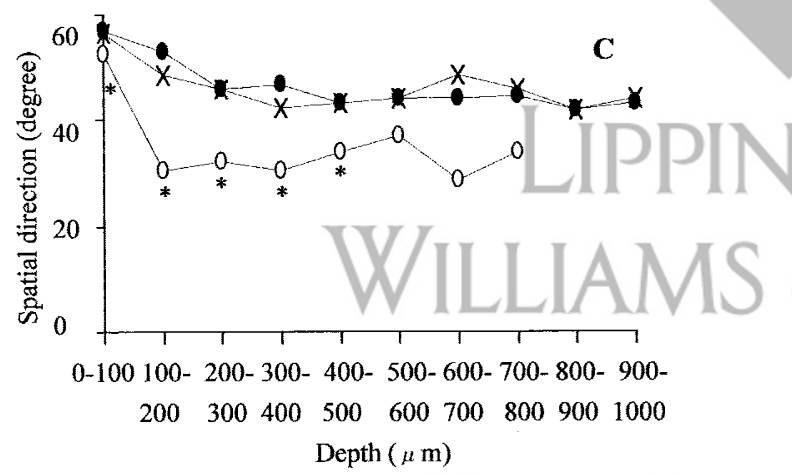

Figure 2.

Microvessel counts (A), microvessel diameter (B), and spatial direction of microvessels (C) as a function of the depth. $\bigcirc$, Normal mucosa; X, colonic carcinoma without metastasis; $\bullet$, colonic carcinoma with metastasis. ${ }^{*}$ Difference is significant at $p<0.05$ or better between normal tissue and carcinoma without metastasis; $\dagger$ significant at $p<0.05$ between carcinoma with or without metastasis; no symbol, not significant.
$>100 \mu \mathrm{m}$ (Fig. 2C). In carcinoma without metastasis, the direction was almost constant regardless of the depth and significantly larger than in normal tissue at a depth $<500 \mu \mathrm{m}$. There was no significant difference in this variable between carcinoma with or without metastasis at any depth.

\section{VEGF Expression Versus Disease Stage}

VEGF expression in three subject groups is shown in Table 2. Carcinoma without metastasis had significantly larger VEGF-positive cell counts (1276 \pm 805$)$ and larger VEGF-positive ratio (53.6 \pm 39.3) than normal tissue $(571 \pm 553$ for VEGF-positive cell counts, $p<0.05 ; 24.6 \pm 23.2$ for VEGF-positive ratio, $p<0.05)$, with no difference in total cell counts $(2312$ \pm 368 for carcinoma without metastasis versus 2610 \pm 1276 for normal tissue, $p=0.26$ ). Compared with carcinoma without metastasis, carcinoma with metastasis had significantly low total cell counts (1443 \pm $237, p<0.001)$ and VEGF-positive cell counts $(716 \pm$ $463, p<0.05)$ but no difference in VEGF-positive ratio $(51.0 \pm 32.6, p=0.90)$.

\section{VEGF Expression as a Function of the Depth}

Total cell count was constant at any depth in normal tissue, whereas it increased to plateau at $600 \mu \mathrm{m}$ in carcinoma as the depth increased (Fig. 3A). In carcinoma without metastasis, VEGF-positive cell counts increased to plateau at $100 \mu \mathrm{m}$ with depth increase, whereas in carcinoma with metastasis, it increased to a peak at $300 \mu \mathrm{m}$, thereafter decreasing. The difference in VEGF-positive cell counts between carcinoma with or without metastasis was significant in the deeper part $>600 \mu \mathrm{m}$ (Fig. 3B). VEGF-positive ratio decreased along with the depth in all subject groups. VEGF-positive ratio was larger in carcinoma with metastasis than in carcinoma without metastasis at a depth of $<700 \mu \mathrm{m}$, but it did not reach the significant level (Fig. 3C).

\section{Discussion}

The current study performed morphometry of microvessels and quantification of VEGF expression in normal and carcinoma tissue with or without metastasis. Analysis of results demonstrated the following

Table 2. VEGF Expression in Normal Carcinoma Without Metastasis and Carcinoma With Metastasis

\begin{tabular}{lccc}
\hline & $\begin{array}{c}\text { Total Cell }\left(/ \mathrm{mm}^{2}\right) \\
\text { Mean } \pm \mathrm{SD}\end{array}$ & $\begin{array}{c}\text { VEGF-Positive Cell }\left(/ \mathrm{mm}^{2}\right) \\
\text { Mean } \pm \text { SD }\end{array}$ & $\begin{array}{c}\text { VEGF-Positive Ratio (\%) } \\
\text { Mean } \pm \text { SD }\end{array}$ \\
\hline Normal & $2312 \pm 368$ & $571 \pm 553$ & $24.6 \pm 23.2$ \\
Carcinoma & & $1276 \pm 805^{b}$ & $53.6 \pm 39.3^{b}$ \\
Without metastasis & $2610 \pm 1276^{a}$ & $716 \pm 463^{d}$ & $51.0 \pm 32.6^{e}$ \\
With metastasis & $1443 \pm 237^{c}$ & \\
\hline
\end{tabular}

${ }^{a}$ Not significant compared with normal.

${ }^{b}$ Differences are significant at $p<0.05$ compared with normal.

${ }^{c}$ Significant at $p<0.001$ compared with carcinoma without metastasis.

${ }^{d}$ Significant at $p<0.05$ compared with carcinoma without metastasis.

${ }^{e}$ Not significant compared with carcinoma without metastasis. 

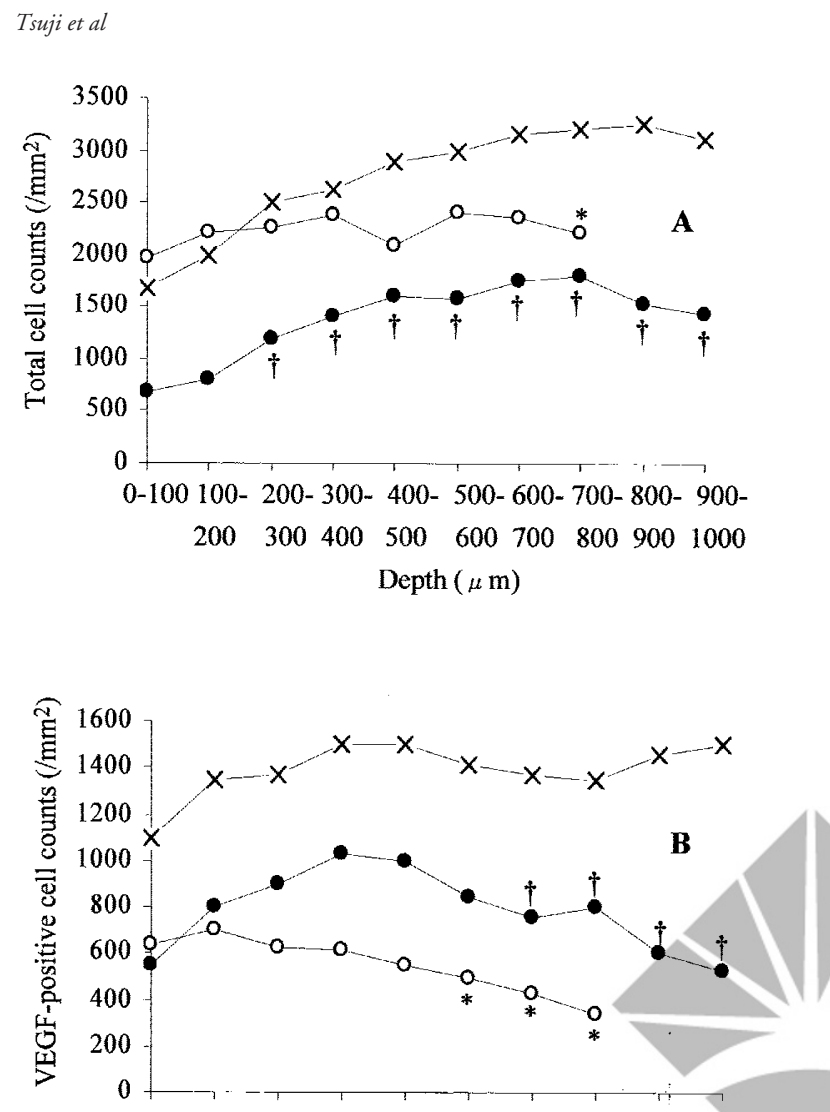

0-100 100- 200-300- 400- 500-600- 700-800- 900$\begin{array}{lllllllll}200 & 300 & 400 & 500 & 600 & 700 & 800 & 900 & 1000\end{array}$ Depth $(\mu \mathrm{m})$

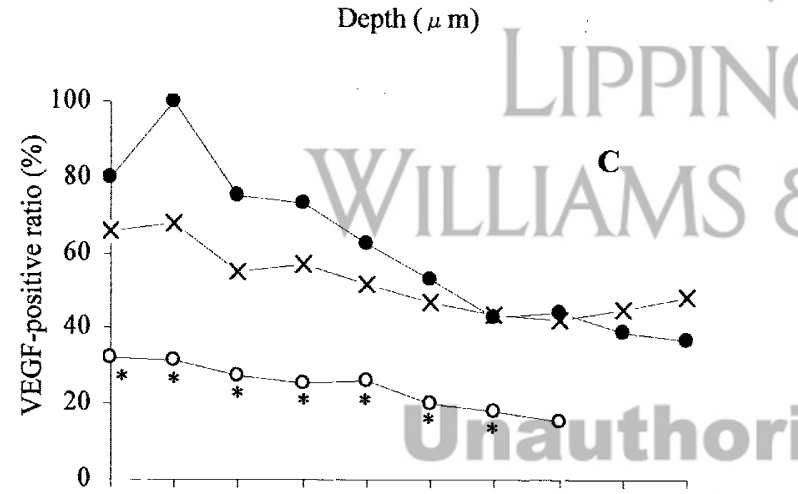

metastasis. (c) The differences in the three morphometric variables between normal tissue and carcinoma without metastasis were significant, especially in shallow parts of the mucosa $(<400 \mu \mathrm{m})$. (d) The mean VEGF-positive cell count was positively correlated with the mean microvessel count but not with the mean microvessel diameter among the three subject groups.

Microvessel counts have been evaluated to characterize colonic carcinoma (Bossi et al, 1995; Frank et al, 1995; Saclarides et al, 1994; Saeki et al, 1997; Takahashi et al, 1995, 1996, 1997, 1998; Tomisaki et al, 1996; Yamaura and Sato, 1974). In these studies, immunostained microvessels have been visually counted under direct observation of a microscopic field at a magnification of $\times 100$ or $\times 200$. In this study, we used a computer-assisted method for quantitative morphometry of microvessels including microvessel counts. This method consists of five sequential procedures: (a) determination of the region of interest in the most vascularized area of digitized microscopic pictures, (b) trace of microvessels identified with reference to the criteria, (c) review by a pathologist, (d) automated measurement of morphometric variables by an image processing software, and (e) storage of the original picture and microvessel trace for further review. Although procedures (a) and (b) still suffered from human intervention, interobserver variation in the procedures was found to be less than 5\% for any morphometric variable, permitting comparative morphometry with acceptable reliability. A fully automated localization or segmentation method for microvessel morphometry will further minimize interobserver variation (Belien et al, 1999).

In present stüdy microvessel counts per $1 \mathrm{~mm}^{2}$ were 192 in the tissue of colonic carcinoma and 144 in normal mucosa. In previous studies when the area of the region of interest was adjusted to $1 \mathrm{~mm}^{2}$, microvessel counts have ranged from 31 (Takahashi et al, 1997) to 181 (Bossi et al, 1995), falling within 100 in most reports (Takahashi et al, 1995; Tokunaga et al, 1999; Tomisaki et al, 1996) for colonic carcinoma and 66 (Bossi et al, 1995) to 89 (Fox et al, 1998) for normal

0-100 100- 200- 300- 400- 500-600- 700-800- 900 $\begin{array}{lllllllll}200 & 300 & 400 & 500 & 600 & 700 & 800 & 900 & 1000\end{array}$ Depth $(\mu \mathrm{m})$

\section{Figure 3.}

Total cell counts (A), vascular endothelial growth factor (VEGF)-positive cell counts (B), and VEGF-positive ratio (C) as a function of the depth. $\odot$, Normal mucosa; $\mathrm{X}$, colonic carcinoma without metastasis; $\bullet$, colonic carcinoma with metastasis. * Difference is significant at $p<0.05$ or better between normal tissue and carcinoma without metastasis; $\dagger$ significant at $p<0.05$ between carcinoma with or without metastasis; no symbol, not significant.

findings: (a) The mean microvessel diameter significantly increased as the pathologic process progressed from normal to carcinoma without metastasis and also increased from carcinoma without metastasis to carcinoma with metastasis. (b) Microvessel counts and spatial direction were significantly larger in carcinoma without metastasis than in normal tissue but did not differ between carcinoma with or without mucosa. This profound difference is attributable at least in part to the selection of the region of interest (invasive edge or inside tumor) in colonic carcinoma. Current study has shown considerable regional differences in microvessel counts of carcinoma tissue: the mean microvessel counts decreased from 250 to 150 as the distance from the surface of the mucosa increased from 0 (invasive edge) to $1000 \mu \mathrm{m}$ (inside tumor). A previous study has also reported similar regional differences in microvessel counts: the invasive edge had about 1.8-fold higher microvessel counts compared with those within the tumor (Takahashi et al, 1995). In normal tissue, the shallowest part of the mucosa (0 to $100 \mu \mathrm{m}$ ) had 2.2-fold higher microvessel counts (221) compared with those (101) in the deeper parts $(>100 \mu \mathrm{m})$. When tissue blocks are sliced parallel to the surface of the mucosa, microvessel counts in normal tissue are underestimated regardless of the region of interest selected. The types of 
antibody used to label the endothelium are a possible cause for the large variation in microvessel counts among studies as well. Tissue slices stained with CD34 have been reported to give 1.8-fold higher microvessel counts than slices stained with factor VIII (Tomisaki et al, 1996). The criteria used for identification of microvessels (single endothelium or clusters of endothelium with or without lumen) may be also responsible for the considerable differences.

Results on the changes in microvessel counts of colonic carcinoma with or without metastasis have varied with investigators. Takahashi et al $(1995,1996$, 1998) and Tomisaki et al (1996) reported that colonic carcinoma with metastasis had significantly larger microvessel counts than that without metastasis; but Saclarides et al (1994) and Bossi et al (1995) found no significant differences in microvessel counts between colonic carcinoma with or without metastasis. Contrary to the results of these studies, the microvessel counts in the current study were larger in carcinoma without metastasis (213) than in that with metastasis (180), although the difference did not reach a significant level. This unexpected result has also been shown in an experimental study of implanted tumor, in which the tumor growth period was divided into four stages according to changes in vascular morphology: Stage 1, slight capillary alterations; Stage 2, formation of fine capillary networks and changes in veins; Stage 3, modifications in arteries; and Stage 4, necrosis (Yamaura and Sato, 1974). Microvessel counts increased to the maximum at Stage 2, thereafter decreasing to nearly 0 at Stage 4 . When the morphometrics of the present study were viewed comparatively using the staging system of those authors, grouping carcinoma without metastasis and that with metastasis to correspond to Stages 2 and 3 , respectively, the results of the present study seemed consistent with the vascular changes they described.

Significant differences in microvessel diameter were seen when comparing normal tissue $(7.03 \mu \mathrm{m})$ to carcinoma without metastasis $(7.99 \mu \mathrm{m})$ to carcinoma with metastasis $(9.75 \mu \mathrm{m})$. Along with the disease stage, the relative frequency of microvessels with a diameter $<10 \mu \mathrm{m}$ decreased: $87 \%$ in normal tissue, $75 \%$ in carcinoma without metastasis, and $64 \%$ in carcinoma with metastasis. In carcinoma with metastasis, microvessels $>60 \mu \mathrm{m}$ have often been found. These large microvessels have never been present in normal tissue or carcinoma without metastasis. Similar results have also been previously reported in an experimental study (Yamaura and Sato, 1974). Their results showed that the number of microvessels $<10$ $\mu \mathrm{m}$ increased from $40 \%$ in Stage 1 to $70 \%$ in Stage 2 . In Stages 3 and 4 , the frequency of microvessels $<10$ $\mu \mathrm{m}$ decreased, and the frequency of microvessels $>10 \mu \mathrm{m}$ increased.

The geometry of the microvessel cross-sections provided the means for determining the spatial direction of the longitudinal axis of microvessels. Microvessels in normal mucosa have shown a well-organized spatial configuration: they were parallel to the mucosal surface in the shallowest part $(<100 \mu \mathrm{m})$ and perpen- dicular in the deeper parts $(>100 \mu \mathrm{m})$. Morphometry of vascular casts from normal mucosa has also shown a similar organization: capillaries are supplied by arterioles from the submucosa and drained into venules only at the surface of the mucosa and venules pass to submucosal veins without receiving any further capillary branches within the mucosa (Skinner et al, 1995). In carcinoma, the mean direction within a depth varied from one tumor to another, and the overall mean direction was almost constant $\left(45^{\circ}\right)$ over a depth from 0 to $1000 \mu \mathrm{m}$, indicating the absence of organized spatial configuration in tumor microvessels. In carcinoma, angiogenesis is associated with tumor cell proliferation, which may occur in a random manner toward the lateral, luminal, or serosal direction. The directions of tumor cell proliferation varied from one location to another even in the same tumor, which may account for the disrupted spatial configuration of tumor microvessels.

Neovascularization is essential for supplying nutrients and removing waste products during tumor cell proliferation (Jain, 1988). Microvessel counts have been reported to correlate with the presence or absence of metastasis (Takahashi et al, 1995, 1996, 1997, 1998; Tomisaki et al, 1996). In the present study, the risk of regional or distant metastasis has been shown to increase as the microvessel diameter increased. Large microvessels $>60 \mu \mathrm{m}$ exclusively observed in carcinoma with metastasis may correspond to the giant capillaries reported by Warren et al (1978). Giant capillaries have been identified as a site for cancer cell intravasation because the endothelial lining of the dilated vessels is thinned out in some regions and tumor cells have been seen within the vessel lumen. In addition to the structural alteration of vascular walls, tumor cells have been shown to increase effective microvessel permeability up to 10 -fold compared with that in normal tissue (Jain and WardHartley, 1987). These structural or functional changes in microvessels may be the dominant parameters responsible for the occurrence of cancer cell intravasation as the first step of metastasis.

In this study the degree of VEGF expression has been reasonably quantified by VEGF-positive cell counts or VEGF-positive ratio because VEGF was expressed in the cytoplasm of benign or malignant epithelial cells. Colonic carcinoma had 2-fold higher VEGF-positive ratio (52\%) compared with normal tissue $(25 \%)$, and the mean VEGF-positive cell counts were shown to be positively correlated with the mean microvessel counts among the three subject groups, supporting the belief that VEGF plays a specific and critical role in blood vessel formation (Dvorak et al, 1999; Ferrara, 1999).

Contrary to our expectation, in carcinoma, tumor cell counts increased as the depth increased, whereas microvessel counts decreased with the depth. The central part of the tumor, therefore, becomes hypoxic compared with the tumor margin, which is likely to be involved in the pathogenesis of central necrosis associated with tumor progression. The spatial profile of microvessel counts responsible for central necrosis 
can be in part explained by that of VEGF expression. When the disease progresses from carcinoma without metastasis to carcinoma with metastasis, a significant decrease in VEGF-positive cell counts occurred in the deeper part of the tumor. Furthermore, a decrement of VEGF-positive ratio against the depth increased from $1.7 \% / 100 \mu \mathrm{m}$ to $4.4 \% / 100 \mu \mathrm{m}$ along with the disease progression. These findings may support a co-option theory that tumor cells seem to survive by angiogenesis at the tumor margin in contrast to regression at the central part (Holash et al, 1999a, 1999b).

Tumor microvessels exhibit abnormal ultrastructure, including endothelial fenestrae, open junctions, and a discontinuous basement membrane (Carmeliet and Jain, 2000; Hashizume et al, 2000). These abnormalities have been found at sites where VEGF and its receptors are overexpressed in tumor (Dvorak et al, 1999). Under topical application of VFGF to normal vasculatures, endothelia of small venules and capillaries present fenestrae or open junctions (Roberts and Palade, 1995). Therefore, it is clear that VEGF is responsible for the abnormal ultrastructure or leaky tumor microvessels. Whether VFGF is involved in the genesis of enlarged microvessels remains to be determined. In this study the mean VEGF-positive cell count was not correlated with the mean microvessel diameter; instead, the spatial profile of the VEGF-positive ratio seemed to parallel that of microvessel diameter in the three subject groups. For further understanding of the mechanisms by which the microvessels are enlarged with tumor progression, the challenge is now to reveal the temporal sequence of VEGF isoforms and/or their receptors or their cooperation with the vascular remodeling factor, angiopoietin-2 (Maisonpierre et al, 1997; Zagazg et al, 1999).

\section{Materials and Methods}

\section{Materials}

Tumor specimens from 36 randomly selected patients with colorectal carcinoma (34 with Borrmann 2 and 2 with Borrmann 3 [Borrmann et al, 1926]) who had undergone surgery at Hirosaki University Hospital between 1996 and 2000 were studied. They consisted of 26 males and 10 females aged 49 to 85 (mean, 66.0) years. Normal histologic parts of the resected colon at least $5 \mathrm{~cm}$ apart from the growth were also examined in all of the cases and served as control. Clinical staging, surgical findings, and pathology reports were reviewed to establish disease stage. The specimens were staged into 14 carcinomas without metastasis (11 cases with Dukes class A [Astler-Coller modification] and 3 with Dukes B) and 22 carcinomas with regional or distant metastasis (19 with Dukes $C$ and 3 with Dukes D).

\section{Immunohistochemistry}

Anti-CD34 Antibody. Four-micrometer-thick sections were prepared from tissue blocks of the colorectal cancer specimen and from normal mucosa $5 \mathrm{~cm}$ apart from the growth, such that the plane of the sections was always perpendicular to the surface of the mucosa. The sections were deparaffinized in $x y-$ lene and rehydrated in graded ethanol solutions (100\%, 95\%, 80\%) and PBS. Immunostaining was preceded by digestion in citric acid $0.01 \mathrm{M}$ for 30 minutes using microwave at $98^{\circ} \mathrm{C}$. After rinsing in PBS, endogenous peroxidase activity was quenched by dipping the sections into $3 \%$ hydrogen peroxide and $100 \%$ methanol for 30 minutes. After rinsing in PBS, the sections were incubated with normal mouse serum for 30 minutes at room temperature. The sections were subsequently incubated with the following: (a) the CD34 monoclonal antibody diluted 1:100 (Dako, Glostrup, Denmark) overnight at $4^{\circ} \mathrm{C}$; (b) secondary antibody (rabbit-anti-mouse antibody, SABPO(M) kit; Nichirei, Tokyo, Japan) for 15 minutes at room temperature; (c) peroxidase-conjugated avidin for 15 minutes at room temperature; and (d) a mixture of $0.1 \%$ hydrogen peroxide and $0.05 \%$ diaminobenzidine for 1 minute. The sections were then counterstained with hematoxylin.

Anti-VEGF Antibody. The deparaffinized section was digested in Tris-buffered saline containing 20\% trypsin (Sigma, Tokyo, Japan) for 10 minutes at $37^{\circ} \mathrm{C}$. After the same preparations as above, the sections were incubated with the following: (a) anti-VEGF monoclonal antibody diluted 1:200 (Santa Cruz Biotechnology, Santa Cruz, California) overnight at $4^{\circ} \mathrm{C}$; (b) secondary antibody (rabbit-anti-mouse antibody, SAB-PO(M) kit; Nichirei) for 15 minutes at room temperature; (c) peroxidase-conjugated avidin for 15 minutes at room temperature; and (d) 3-amino-9-ethyl carbazole (Dako). The sections were counterstained with hematoxylin.

\section{Quantitative Morphometry of Microvessels}

Slides were examined at low-power magnification $(\times 40)$ to identify the area with the highest density of microvessels. In this study the most vascularized area was localized around the lateral margin of the surface of the growth, without exception. In this area, the rectangular region of interest for analysis with a width of 800 to $1000 \mu \mathrm{m}$ and a height of $1000 \mu \mathrm{m}$ was placed such that the upper side would meet the line of the mucosal surface. In sections from normal parts of the colon, the height of the region of interest equaled the thickness of the lamina propria, ranging from 200 to $800 \mu \mathrm{m}$. The picture of the region of interest $(\times 100)$ was digitized and saved on a computer hard disk for analysis or review. The spatial resolution of the digitized picture was $1.08 \mu \mathrm{m} /$ pixel, which was small enough to identify blood vessels with a diameter less than $2 \mu \mathrm{m}$. The picture was transferred to a personal computer and $x$ and $y$ coordinates were defined in the region of interest: the left-upper corner for the origin, the upper side (the mucosal surface) for the $x$ axis, and the left side for the $y$ axis representing the distance from the mucosal surface (Fig. 4). The use of antiCD34 antibody provided reliable and selective immunostaining of vascular endothelial cells. Tumor cells, as well as other normal tissue constituents, were consistently unstained. Single-cell layers or clusters of endothelial cells with a lumen were considered as 


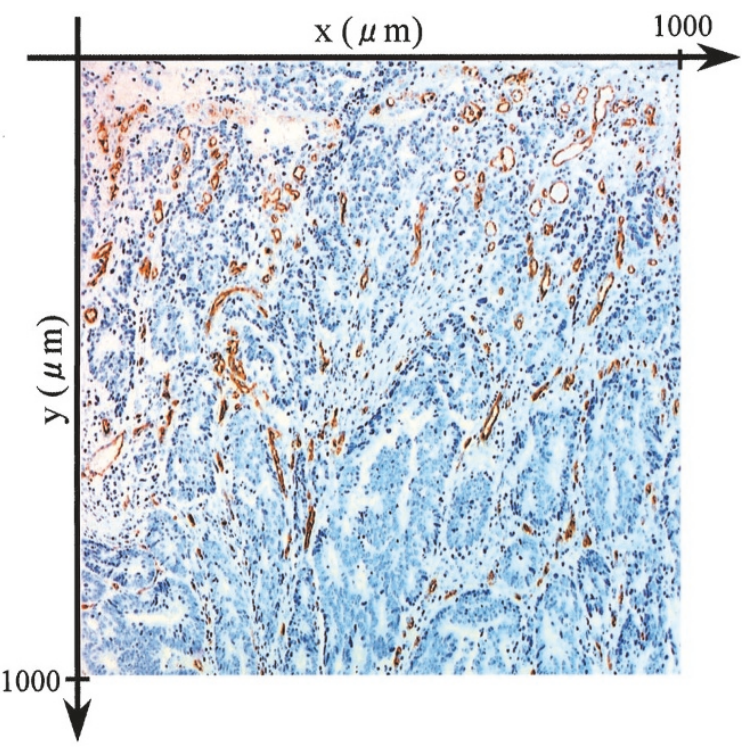

Figure 4.

An example of the region of interest for measuring the vascular morphometric variables in the most vascularized area of colonic carcinoma immunostained with CD34 ( $\times 100)$. The left-upper corner for the origin, the upper side for the $x$ axis (the line of the mucosal surface), and the left side for the $y$ axis representing the distance from the mucosal surface. To perform morphometry, the cross-section of the microvessels was automatically numbered and processed for the geometrical center $(x, y)$, the length of major axis or minor axis, and the angle made between the major axis and the $x$ axis.

individual microvessels. All of the stained blood microvessels in the region of interest were manually traced by a mouse device. By using image processing software (Scion Image for Windows, Scion Corporation, Frederick, Maryland), the cross-section of microvessels was automatically numbered/and processed for the geometrical center of the lumen $(x, y)$, the length of the minor axis or major axis, and the angle between the major axis and the above-stated $x$ axis. The diameter of each microvessel was defined as the length of the minor axis. Furthermore, the spatial direction of the longitudinal axis of microvessels at the level of the slice plane was calculated by using the length of the minor and major axes and the angle, and expressed by the angle made between the calculated direction and the $y$ axis, ranging from 0 to $90^{\circ}$. The longitudinal axis of the microvessel is perpendicular to the mucosal surface at an angle of $0^{\circ}$ and parallel at $90^{\circ}$. These variables were processed for the morphometric variables, including microvessel counts per unit area (per $\mathrm{mm}^{2}$ ), the mean diameter of microvessels $(\mu \mathrm{m})$, and the mean spatial direction (degree). To examine changes in each variable as a function of the depth, they were also calculated at every 100- $\mu \mathrm{m}$ depth.

Determination of the region of interest and microvessel trace was performed in all of the cases by a single examiner (TT); $30 \%$ of the cases, randomly selected, were analyzed by another examiner (NH). All of the traces were reviewed by a pathologist unaware of the study design (MT). Interobserver variation between the two investigators was found to be less than $5 \%$ for any morphometric variable.

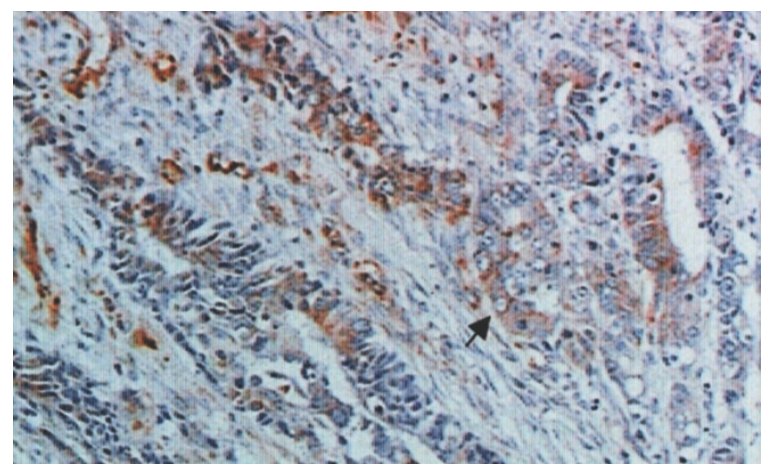

Figure 5.

Slide from a colonic carcinoma immunostained with anti-VEGF antibody ( $\times 100)$. Note VEGF expression in the cytoplasm of the epithelial cells (arrow) with no background staining. Total epithelial cell counts (per $\mathrm{mm}^{2}$ ), VEGFpositive cell counts (per $\mathrm{mm}^{2}$ ), and VEGF-positive ratio (\%) were evaluated in the region of interest.

\section{Evaluation of VEGF Expression}

The picture of the slide immunostained with anti-VEGF antibody $(\times 100)$ was transferred to a personal computer. The region of interest for VEGF expression was strictly adjusted to that for microvessel morphometry. VEGF was expressed in the cytoplasm of the epithelial cells with no background staining (Fig. 5). The total numbers of epithelial cells and VEGF-positive cells in the region of interest were visually counted for total epithelial cell counts per unit area (per $\mathrm{mm}^{2}$ ), VEGFpositive cell counts (per $\mathrm{mm}^{2}$ ), and VEGF-positive ratio (\%). The parameters were also calculated at every $100-\mu \mathrm{m}$ depth.

\section{Statistical Analysis}

Data are expressed as means \pm SD. Statistical significance was evaluated using Student's or Welch's unpaired $t$ test. Differences between means were considered significant if the $p$ values were equal to or less than 0.05 .

\section{References}

Belien JA, Somi S, de Jong JS, van Diest PJ, and Baak JP (1999). Fully automated microvessel counting and hot spot selection by image processing of whole tumour sections in invasive breast cancer. J Clin Pathol 52:184-192.

Borrmann R, Henke F, and Lubarsch O (1926). Handbuch der speziellen pathologischen Anatomie and Histologie, vol 4. Berlin: Springer, 865.

Bossi P, Viale G, Lee AK, Alfano R, Coggi G, and Bosari S (1995). Angiogenesis in colorectal tumors: Microvessel quantitation in adenomas and carcinomas with clinicopathological correlations. Cancer Res 55:5049-5053.

Carmeliet P and Jain RK (2000). Angiogenesis in cancer and other diseases. Nature 407:249-257.

Dvorak HF, Nagy JA, Feng D, Brown LF, and Dvorak AM (1999). Vascular permeability factor/vascular endothelial growth factor and the significance of microvascular hyperpermeability in angiogenesis. Curr Top Microbiol Immunol 237:97-132. 
Ferrara N (1999). Vascular endothelial growth factor: Molecular and biological aspects. Curr Top Microbiol Immunol 237:1-30.

Fox SH, Whalen GF, Sanders MM, Burleson JA, Jennings K, Kurtzman S, and Kreutzer D (1998). Angiogenesis in normal tissue adjacent to colon cancer. J Surg Oncol 69:230-234.

Frank RE, Saclarides TJ, Leurgans S, Speziale NJ, Drab EA, and Rubin DB (1995). Tumor angiogenesis as a predictor of recurrence and survival in patients with node-negative colon cancer. Ann Surg 222:695-699.

Hashizume H, Baluk P, Morikawa S, McLean JW, Thurston G, Roberge S, Jain RK, and McDonald DM (2000). Openings between defective endothelial cells explain tumor vessel leakiness. Am J Pathol 156:1393-1380.

Holash J, Maisonpierre PC, Compton D, Boland P, Alexander CR, Zagzag D, Yancopoulos GD, and Wiegand SJ (1999a). Vessel cooption, regression, and growth in tumors mediated by angiopoietins and VEGF. Science 284:1994-1998.

Holash J, Wiegand SJ, and Yancopoulos GD (1999b). New model of tumor angiogenesis: Dynamic balance between vessel regression and growth mediated by angiopoietins and VEGF. Oncogene 18:5356-5362.

Jain RK (1988). Determinants of tumor blood flow: A review. Cancer Res 48:2641-2658.

Jain RK and Ward-Hartley KA (1987). Dynamics of cancer cell interaction with microvasculature and interstitium. Biorheology 24:117-125.

Maisonpierre PC, Suri C, Jones PF, Bartunkova S, Wiegand SJ, Radziejewski C, Compton D, McClain J, Aldrich TH, Papadopoulos N, Daly TJ, Davis S, Sato TN, and Yancopoulos GD (1997). Angiopoietin-2, a natural antagōnist for Tie2 that disrupts in vivo angiogenesis. Science 227:55-60.

Roberts WG and Palade GE (1995). Increased microvascular permeability and endothelial fenestration induced by vascular endothelial growth factor. J Cell Sci 108:2369-2379.

Saclarides TJ, Speziale NJ, Drab E, Szeluga DJ, and Rubin DB (1994). Tumor angiogenesis and rectal carcinoma. Dis Colon Rectum 37:921-923.

Saeki T, Tanada M, Takashima S, Takashima SH, Saeki H, Takiyama W, Nishimoto N, and Moriwaki S (1997). Correlation between expression of platelet-derived endothelial cell growth factor (thymidine phosphorylase) and microvessel density in early-stage human colon carcinomas. Jpn $\mathrm{J}$ Clin Oncol 27:227-230.
Skinner SA, Frydman GM, and O'Brien PE (1995). Microvascular structure of benign and malignant tumors of the colon in humans. Dig Dis Sci 40:373-384.

Takahashi Y, Kitadai Y, Bucana CD, Cleary KR, and Ellis LM (1995). Expression of vascular endothelial growth factor and its receptor, KDR, correlates with vascularity, metastasis, and proliferation of human colon cancer. Cancer Res 55: 3964-3968.

Takahashi Y, Bucana CD, Liu W, Yoneda J, Kitadai Y, Cleary KR, and Ellis LM (1996). Platelet-derived endothelial cell growth factor in human colon cancer angiogenesis: Role of infiltrating cells. J Natl Cancer Inst 88:1146-1151.

Takahashi Y, Tucker SL, Kitadai Y, Koura AN, Bucana CD, Cleary KR, and Ellis LM (1997). Vessel counts and expression of vascular endothelial growth factor as prognostic factors in node-negative colon cancer. Arch Surg 132:541-546.

Takahashi Y, Bucana CD, Cleary KR, and Ellis LM (1998). p53, vessel count, and vascular endothelial growth factor expression in human colon cancer. Int J Cancer (Pred Oncol) 79:34-38.

Tokunaga T, Nakamura M, Oshika Y, Abe Y, Ozeki Y, Fukushima Y, Hatanaka H, Sadahiro S, Kijima H, Tsuchida T, Yamazaki H, Tamaoki N, and Ueyama Y (1999). Thrombospondin 2 expression is correlated with inhibition of angiogenesis and metastasis of colon cancer. $\mathrm{Br} \mathrm{J}$ Cancer 79:354-359.

Tomisaki S, Ohno S, Ichiyoshi Y, Kuwano H, Maehara Y, and Sugimachi K (1996). Microvessel quantification and its possible relation with liver metastasis in colorectal cancer. Cancer 77:1722-1728.

Yamaura H and Sato H (1974). Quantitative studies on the developing vascular system of rat hepatoma. J Natl Cancer Inst 53:1229-1240.

Warren BA, Shubik P, and Feldman R (1978). Metastasis via the blood stream: The method of intravasation of tumor cells in a transplantable melanoma of the hamster. Cancer Lett 4:245-251.

Zagazg D, Hooper A, Friedlander DR, Chan W, Holash J, Wiegand SJ, Yancopoulos GD, and Grumet M (1999). In situ expression of angiopoietins in astrocytomas identifies angiopoietin-2 as an early marker of tumor angiogenesis. Exp Neurol 159:391-400. 